\title{
ESTADO Y PATRIMONIO NACIONAL EN NICARAGUA (1944-1979)
}

Chester Urbina Gaitán

\begin{abstract}
Resumen
Las declaratorias patrimoniales emitidas durante el régimen de la dictadura somocista, demuestran un concepto de patrimonio anclado únicamente en la parte material de este. Asimismo, evidencian que el concepto de identidad nacional de los Somoza giró alrededor del legado urbanísticoarquitectónico, creado en la colonia y en el siglo XIX. En esto sobresale la preservación del sitio donde ocurrió la Batalla de San Jacinto. Con todo esto, los Somoza señalan una política de modernización y de transmisión de valores patrios alrededor de cierta visión de la historia y de un pasado compartido, aunque la costa caribeña quedó fuera de esta imagen nacional.
\end{abstract}

Palabras clave: Patrimonio Nacional, Estado, Nicaragua, Dictadura Somocista, Identidad Nacional,

\begin{abstract}
:
Heritage Acts emitted by Somoza dictatorship regime shown a heritage concept only related to the material part of this. Also evidence that Somoza's concept of national identity was related to urban architectonic inheritance, built on colonial period of the XIX century. Excel preservation of San Jacinto Battle site. This fact showed a police of transmission of patriotic values and modernization, based on historical point of view and shared past. Although Caribean Coast was left out of this national visualization.
\end{abstract}

Keywords: National heritage, Nicaragua, National Identity, Somoza Dictatorship.

\section{Introducción}

Para Iván Molina y Patricia Fumero, en el surgimiento de la comunidad política imaginada nicaragüense, se enfatizó el vínculo existente durante el siglo XIX, entre el proyecto canalero y la constante amenaza exterior. Fue en este contexto que se creó en Nicaragua un vocabulario nacionalista y una imagen nacional. Empero, este proceso no se creó únicamente, en torno a la construcción del canal interoceánico. Tal es el caso de la promoción de la Batalla de San Jacinto y del héroe José Dolores Estrada durante el período de estabilidad política de los "Treinta Años Conservadores" (1857-1893) (Molina y Fumero: 1997; 14).

La Batalla de San Jacinto, junto con el rescate de Estrada, un héroe al que se le adscribieron los valores más tradicionales de las clases subordinadas -la humildad, el valor, la lealtad y el patriotismo-, facilitaron el avance del proceso de invención de la nación nicaragüense por parte del Estado (Molina y Fumero: 1997; 27). Esto matiza la idea de Víctor Hugo Acuña en torno a que: "El Estado creado por los conservadores dejó, por tanto, una centralización política incompleta $\mathrm{y}$, además, poco se ocupó de los problemas de su legitimación, es decir, poco avanzó en el proceso de invención de la nación (https://www.american.edu/clals/ upload/264n-del-Estado-en-Nicaragua-yCosta-Rica-en-perspectiva-comparada.pdf (Fecha de consulta: 2 de febrero de 2014)."

Visto desde otro ángulo, la historiadora Frances Kinloch señala que en Nicaragua la derrota de William Walker no se convirtió 
en una posibilidad de exaltar la imagen de los nicaragüenses como conjunto social. Al contrario, se reconoció la propia inferioridad étnica donde se descubrió el peso de la imagen atribuida a los pueblos del trópico por el pensamiento antropológico ilustrado [las ideas de la degradación de "la raza americana" y su incapacidad para autogobernarse], e incluso la influencia de la tesis sobre la superioridad de la raza anglosajona, esgrimida por los propagandistas del Destino Manifiesto. Empero, la elite política refirió esta inferioridad a los sectores subordinados y se reservó para sí el rol de diseminadores de la civilización europea, aunque después de casi treinta años de transitar en la anarquía la elite política comenzó a perder la esperanza en cuanto a su capacidad para instituir gobiernos estables, lo cual atribuyeron a la herencia cultural española e, incluso, a la sangre de sus ancestros (Kinloch: 2001; 198).

Para Guillermo Fernández, el análisis de los discursos y las representaciones sobre la nación transmitido en los textos utilizados para la enseñanza de la historia de Nicaragua entre 1873 y1930 concluye que, entre 1893 y 1909 la nación correspondía el territorio donde se ha nacido. En este caso, Nicaragua también alentaba la idea de que el país era un fragmento de una patria más grande, Centroamérica.

Después dela caída de Zelaya, los gobernantes nacionales impregnaron el contenido de los textos de historia con su propia fe confesional católica, de manera que en su concepto de patria se evidencia una fusión y confusión entre patriotismo, sentimiento de nacionalidad y fe religiosa católica. Esta visión se mantuvo con la dictadura de los Somoza (1937-1979); de modo que su influencia se sentirá con fuerza hasta finales de los años setentas (http:/ / escuelahistoria. fcs.ucr.ac.cr/contenidos/articulos/2008/ especial2008/articulos/04-Cultural/46.pdf (Fecha de consulta: 1 de marzo de 2014).
Con respecto al concepto de patrimonio, se tiene la definición elaborada por la Conferencia Mundial de la UNESCO sobre el Patrimonio Cultural, celebrada en México en el año 1982: “El Patrimonio Cultural de un pueblo comprende las obras de sus artistas, arquitectos, músicos, escritores y sabios, así como las creaciones anónimas, surgidas del alma popular, y el conjunto de valores que dan sentido a la vida, es decir, las obras materiales y no materiales que expresan la creatividad de ese pueblo; la lengua, los ritos, las creencias, los lugares y monumentos históricos, la literatura, las obras de arte y los archivos y bibliotecas (Conferencia Mundial de la UNESCO sobre el Patrimonio Cultural, celebrada en México en el año 1982. s.p.)".

Fundamentado en todo lo anterior, este ensayo pretende estudiar la posición del Estado nicaragüense en la transmisión de un sentimiento de pertenencia nacional a través de la protección del Patrimonio Nacional durante el período de 1944 a 1979.

\section{Estado y Patrimonio Nacional en Nicaragua (1944-1979)}

Sobre la posición del Estado nicaragüense en la preservación de su Patrimonio Nacional, se sabe que en 1944 se declararon monumentos nacionales históricos, la iglesia de San Juan Bautista y la de la Parroquia de Sutiava, de la ciudad de León; la iglesia de La Concepción de la ciudad de El Viejo y la de Guadalupe de la ciudad de Granada. El Estado se haría cargo de los gastos de la reparación de las mencionadas iglesias, debiéndose poner de acuerdo para esto con las autoridades eclesiásticas encargadas de las mismas. A cada templo se le asignaría la cantidad de hasta mil córdobas mensuales para los trabajos de reparación. Estas sumas serían tomadas del Presupuesto General de Gastos que señalara el Poder Ejecutivo y debían ser incluidas en los próximos Presupuestos Generales de Gastos de la Nación, hasta la 
terminación de los trabajos (La Gaceta No. 198 del 21 de Septiembre de 1944. Managua, s.p.).

En años posteriores, durante la década del cincuenta, se declararon Monumentos Históricos las iglesias parroquiales de Juigalpa, Acoyapa y Comalapa (La Gaceta No.
167 del 12 de Agosto de 1950. Managua, s.p.). Según se puede observar, la conservación del patrimonio histórico-arquitectónico de Nicaragua giraba alrededor de la preservación de los principales templos católicos. Esto queda más claro en el Cuadro No.1 que se presenta a continuación:

\section{CUADRO NO.1 \\ PATRIMONIO NACIONAL DE NICARAGUA (1944-1979)}

\begin{tabular}{|c|c|c|}
\hline INMUEBLE DECLARADO & $\begin{array}{l}\text { TIPO DE } \\
\text { DECLARATORIA }\end{array}$ & PUBLICACION EN LA GACETA \\
\hline Iglesia de San Juan Bautista & Monumento Nacional & No.198 del 21 de septiembre de 1944 \\
\hline Iglesia de la Parroquia de Subtiava & Monumento Nacional & No.198 del 21 de septiembre de 1944 \\
\hline Iglesia de La Concepción del Viejo & Monumento Nacional & No.198 del 21 de septiembre de 1944 \\
\hline Iglesia de Guadalupe de Granada & Monumento Nacional & No.198 del 21 de septiembre de 1944 \\
\hline Templo de Guadalupe de León & $\begin{array}{l}\text { Monumento Nacional } \\
\text { Histórico }\end{array}$ & No. 247 del 15 de Noviembre de 1946 \\
\hline $\begin{array}{l}\text { Templo parroquial de Santa Ana, } \\
\text { de Niquinohomo }\end{array}$ & $\begin{array}{l}\text { Monumento Nacional } \\
\text { Histórico }\end{array}$ & No. 274 del 18 de Diciembre de 1946 \\
\hline Templo de Jinotega & $\begin{array}{l}\text { Monumento Nacional } \\
\text { Histórico }\end{array}$ & No. 109 del 26 de Mayo de 1947 \\
\hline $\begin{array}{l}\text { Un lote de terreno de } 4 \text { manzanas } \\
\text { de la Finca "San Jacinto" }\end{array}$ & $\begin{array}{l}\text { Monumento Nacional } \\
\text { Histórico }\end{array}$ & No. 140 del 29 de Junio de 1949 \\
\hline Iglesia Parroquial de Juigalpa & Monumento Histórico & No.167 del 12 de agosto de 1950 \\
\hline Iglesia Parroquial de Acoyapa & Monumento Histórico & No.167 del 12 de agosto de 1950 \\
\hline Iglesia Parroquial de Comalapa & Monumento Histórico & No.167 del 12 de agosto de 1950 \\
\hline Teatro Municipal de León & Monumento Histórico & No. 259 del 6 de Diciembre de 1950 \\
\hline $\begin{array}{l}\text { Templo Parroquial de Santa Ana de } \\
\text { Nindirí }\end{array}$ & $\begin{array}{l}\text { Monumento Nacional } \\
\text { Histórico }\end{array}$ & No.254 del 10 de noviembre de 1954 \\
\hline $\begin{array}{l}\text { Templo parroquial de Camoapa, } \\
\text { Departamento de Boaco }\end{array}$ & Monumento Nacional & No.292 del 23 de Diciembre de 1955 \\
\hline $\begin{array}{l}\text { Templo parroquial de de Nagarote, } \\
\text { Departamento de León }\end{array}$ & Monumento Nacional & No.292 del 23 de Diciembre de 1955 \\
\hline Templo de San Jerónimo de Masaya & Monumento Histórico & No.202 del 4 de Septiembre de 1956 \\
\hline Templos de Diria & Monumento Histórico & No.254 del 8 de Noviembre de 1956 \\
\hline Templo de Diriomo & Monumento Histórico & No.254 del 8 de Noviembre de 1956 \\
\hline $\begin{array}{l}\text { Templo de El Calvario de } \\
\text { Chinandega }\end{array}$ & Monumento Histórico & No. 265 del 21 de Noviembre de 1961 \\
\hline $\begin{array}{l}\text { Templo Parroquial de Santa } \\
\text { Catarina de Namotiva, Catarina }\end{array}$ & $\begin{array}{l}\text { Monumento Nacional } \\
\text { Histórico }\end{array}$ & No.76 del 30 de marzo de 1963 \\
\hline Iglesia Parroquial de Posoltega & $\begin{array}{l}\text { Monumento Nacional } \\
\text { Histórico }\end{array}$ & No.76 del 30 de marzo de 1963 \\
\hline
\end{tabular}




\begin{tabular}{|c|c|c|}
\hline Iglesia Parroquial de Potosí, Rivas & $\begin{array}{l}\text { Monumento Nacional } \\
\text { Histórico }\end{array}$ & No.76 del 30 de marzo de 1963 \\
\hline Iglesia Parroquial de Somoto & Monumento Nacional & No.261 del 14 de noviembre de 1964 \\
\hline $\begin{array}{l}\text { Exploración arqueológica para } \\
\text { encontrar el sitio donde fue } \\
\text { construida la ciudad de León Viejo }\end{array}$ & Interés Nacional & No. 176 del 5 de Agosto de 1967 \\
\hline Cerro Coyotepe & Monumento Nacional & No. 260 del 15 de noviembre de 1967 \\
\hline Cerro La Barranca & Monumento Nacional & No. 260 del 15 de noviembre de 1967 \\
\hline $\begin{array}{l}\text { La Cruz de Lorena situada entre } \\
\text { Rivas y San Jorge }\end{array}$ & $\begin{array}{l}\text { Interés Nacional } \mathrm{y} \\
\text { Cultural }\end{array}$ & No.11 del 13 de enero de 1968 \\
\hline Templo parroquial de Tipitapa & $\begin{array}{ll}\text { Interés } & \text { Cultural } \\
\text { Nacional } & \\
\end{array}$ & No.11 del 13 de enero de 1968 \\
\hline $\begin{array}{l}\text { Iglesia de Nuestra Señora de } \\
\text { Guadalupe de Chichigalpa }\end{array}$ & $\begin{array}{ll}\text { Interés } & \text { Cultural } \\
\text { Nacional } & \end{array}$ & No.109 del 17 de mayo de 1968 \\
\hline $\begin{array}{l}\text { Ruinas de la iglesia de San Francisco } \\
\text { de El Realejo }\end{array}$ & Interés Cultural & No. 127 del 7 de junio de 1968 \\
\hline Iglesia de San Francisco de Granada & Monumento Nacional & No.131 del 13 de junio de 1969 \\
\hline $\begin{array}{l}\text { Iglesia Parroquial de Nuestra } \\
\text { Señora Santa Ana de Nandaime }\end{array}$ & Monumento Nacional & No.215 del 22 de septiembre de 1970 \\
\hline $\begin{array}{l}\text { Iglesia Parroquial de San Nicolás } \\
\text { de Tolentino de La Paz Centro }\end{array}$ & $\begin{array}{l}\text { Monumento Histórico } \\
\text { Nacional }\end{array}$ & No. 39 del 16 de febrero de 1971 \\
\hline $\begin{array}{l}\text { Las Plazas de los Leones e } \\
\text { Independencia, el Parque Cristóbal } \\
\text { Colón, la Iglesia de San Francisco } \\
\text { y su Convento vecino, y los Muros } \\
\text { de Jalteva de la Ciudad de Granada } \\
\text { así como las áreas circundantes que } \\
\text { integran una sola unidad de paisaje }\end{array}$ & $\begin{array}{l}\text { Monumentos } \\
\text { Nacionales }\end{array}$ & No. 284 del 12 de diciembre de 1974 \\
\hline 1975-1979 & --- & --- \\
\hline
\end{tabular}

Fuente: La Gaceta 1944-1979. Managua: Imprenta Nacional.

Del análisis de los datos del cuadro anterior, se infiere que de las 34 declaratorias patrimoniales $27(79 \%)$ correspondieron a templos, $2(6 \%)$ recayeron sobre las ruinas de las ciudades fundadas por los españoles como León Viejo y Granada, 2 (6 \%) sobre cerros donde ocurrieron hechos militares, una declaratoria (3\%) se asentó sobre el terreno donde se efectuó la Batalla de San Jacinto, otra sobre un teatro (3\%) y la última (3\%) se hizo sobre una cruz. Esto permite señalar que las declaratorias patrimoniales de Nicaragua del período 1944-1979 se concentraron en la promoción de la identidad nacional ligada al legado urbanístico-arquitectónico de las épocas coloniales y republicanas del siglo XIX.
Debe señalarse que las declaratorias patrimoniales anteriores, se concentraron en las zonas Pacífica y Central de Nicaragua y ninguna se hizo sobre algún edificio o hecho histórico de la zona caribeña. Esta posición política radicó en la visión que los Somoza tenían de la historia, de los hechos históricos y de su concepto de nación, principalmente de la Batalla de San Jacinto. Al respecto véanse los siguientes textos:

Nos separamos de la Madre Patria pacíficamente, sin efusión de sangre, como sujetos a la fatalidad de un ciclo histórico. No hubo guerra de independencia para separarnos de España. Nuestra epopeya fue la cruzada 
contra quienes, treinta y cuatro años más tarde, pretendieron imponer su cruel señorío con el cínico apoyo de poderosos amigos, partidarios de la esclavitud (Discurso de Anastasio Somoza García con motivo del Centenario de la Batalla de San Jacinto. Managua: Talleres Nacionales, 1956, 8)".

“...la Patria Nicaragüense se forjó en la conquista y la dominación española, que duró un poco más de tres centurias... Patria, que es territorio común, economía coordinada, organización jurídica original, lengua y cultura propias... Nicaragua vive y sobrevive, porque existe de verdad; porque al cabo de 150 años, es una nación real, forjada por la historia, construida a través de luchas formidables; y porque es un cuerpo nacional viviente, con pasado, presente y futuro,...(Novedades. Viernes 17 de septiembre de 1971.

En la cita del discurso de Somoza García, es evidente el papel de la Guerra Nacional (la gesta contra los filibusteros) en la formación del origen de la nación nicaragüense. La Guerra Nacional fungió como guerra de independencia sustituta. Por su parte, su hijo Anastasio Somoza Debayle, emitió una alocución donde se usa la historia para crear un tipo particular de memoria histórica, definidora de una identidad colectiva nicaragüense. En este discurso, se hace referencia a los rasgos comunes de los nicaragüenses forjados a través del tiempo, donde el poder estatal del país está conjugado con los elementos culturales de la nación.

Es notoria la influencia de Ernest Renan con respecto a la continuidad en el futuro de la nación, del pasado y el presente. El pensamiento nacionalista de Renan contiene las ideas referentes a que todas las naciones tienen una misión que cumplir y el destino le depara una grandeza a la nación. Para Renan (1987):

Una nación es pues una gran solidaridad, constituida por el sentimiento de los sacrificios que se han hecho y los sacrificios que todavía se está dispuesto a hacer. Supone un pasado; se resume, no obstante en el presente por un hecho tangible: el consentimiento, el deseo claramente expresado de continuar la vida en común. La existencia de una nación (perdonad esta metáfora) es un plebiscito de todos los días, así como la existencia individual es una afirmación perpetua de vida (pp. 82-83).

Sobre las políticas culturales del régimen de los Somoza, Miguel Ayerdis en su estudio sobre el tema, ha señalado que entre las características más notables del gobierno del General Anastasio Somoza García está el fomento de una política nacionalista que apelaba a valores y sentimientos "patrios" sustentados en tradiciones compartidas. El fin político estratégico de esta política estatal, pasaba por la necesidad de la modernización del Estado y de la sociedad y por supuesto, de la perpetuación en el poder..(Revista de Historia: 2006; 138). Con las celebraciones de la Semana de la Patria y la Promesa de la bandera son reelaboradas y relanzadas con el propósito de articular una nueva visión cultural, para construir un discurso nacionalista.. (Revista de Historia: 2006; 139). Lo mismo se buscaba con la celebración de la fiesta nacional dariana de 1941 (http:// istmo.denison.edu/n10/articulos/fiesta. html s.p. [Fecha de consulta: 15 de febrero de 2014]).

Para 1968 se establece la Comisión Nacional de Protección al Patrimonio HistóricoArtístico. La Comisión que crea esta ley estaría integrada por un representante de las siguientes entidades: La Academia de Geografía e Historia, la Oficina Nacional de Urbanismo, el Consejo Técnico de la Escuela de Arquitectura de la Universidad Nacional Autónoma de Nicaragua, el Instituto Histórico de la Universidad Centroamericana, la División de Extensión 
Cultural del Ministerio de Educación Pública, la Asociación de Ingenieros y Arquitectos, la Dirección General de Turismo, el Archivo General de la Nación, el Instituto Nicaragüense de Antropología y Arqueología, el Partido de la Minoría.

Los miembros que integraban la Comisión Nacional de Protección al Patrimonio... desempeñarían sus cargos ad-honorem. La Comisión así integrada debía realizar en forma inmediata un inventario de los conjuntos o lugares históricos-artísticos, urbanos y rurales existentes en el país. Se considerarían los centros urbanos de las ciudades de Granada y León, como conjuntos cuya integridad de estilo arquitectónico debían preservarse.

La Comisión, de acuerdo con los respectivos Concejos Municipales establecería los límites de dichos conjuntos y dictaría las medidas protectoras del caso. Se prohibía la exportación definitiva de ídolos, armas, cerámica y demás objetos antiguos, con el propósito de que continúen formando parte del tesoro cultural de la Nación. El Poder Ejecutivo, por medio del Ministerio de Educación Pública y dentro de los sesenta días posteriores a la promulgación de esta Ley, dictaría el Reglamento de la misma, en el que debería establecer las normas a que debían sujetarse la extracción, circulación, conservación y venta de ídolos, armas, cerámica y demás objetos antiguos. Las construcciones que con anterioridad han sido declaradas monumentos nacionales no podrían ser remodeladas o reconstruidas sin previo sometimiento y aprobación de los planos por la COMISIÓN NACIONAL creada por esta Ley (La Gaceta No. 238 del 18 de Octubre de 1968. Managua, s.p.).

Según se observa en la configuración de la Comisión y de sus funciones, el concepto que se manejaba sobre patrimonio radicaba en centros urbanos coloniales, ídolos, armas y objetos antiguos principalmente de cerámica, no contemplándose otros elementos constitutivos del patrimonio, como obras artísticas, archivos, bibliotecas, ritos y creencias. Sin embargo, se demuestra el interés de los gobernantes del período analizado por preservación del cierto patrimonio cultural nicaragüense.

\section{Conclusión}

Las declaratorias patrimoniales emitidas durante la dictadura somocista, evidencian un concepto de identidad nacional nicaragüense que giró alrededor del legado urbanísticoarquitectónico creado en la colonia y en el siglo XIX. Con esta concepción, se buscaba identificar al país con la cultura occidental europea. En este espacio temporal sobresale la preservación del sitio donde ocurrió la Batalla de San Jacinto.

La conservación y protección del patrimonio nacional nicaragüense durante el régimen dictatorial de los Somoza, evidencia una política de modernización y de transmisión de valores patrios alrededor de cierta visión de la historia. De un pasado compartido, aunque la costa caribeña quedaría al margen de esta construcción imaginaria de la nación nicaragüense.

\section{Referencias bibliográficas}

\section{Periódico}

1. Novedades. Viernes 17 de septiembre de 1971. Año XXXV. No.11405. Managua.

\section{Discurso}

1. Discurso de Anastasio Somoza García con motivo del Centenario de la Batalla de San Jacinto. Managua: Talleres Nacionales, 1956.

\section{Documento}

1. Conferencia Mundial de la UNESCO sobre el Patrimonio Cultural, celebrada en México en el año 1982. 


\section{La Gaceta}

1. La Gaceta. No. 198 del 21 de Septiembre de 1944. Managua.

2. La Gaceta. No. 167 del 12 de Agosto de 1950. Managua.

3. La Gaceta. No. 238 del 18 de Octubre de 1968. Managua.

\section{Libros}

1. Memorias del IV Simposio Panamericano de Historia. (2001) México: Instituto Panamericano de Geografía e Historia.

2. Molina Jiménez, I. y Fumero Vargas, P. (1997). La sonora libertad del viento. Sociedad y cultura en Costa Rica y Nicaragua (18211914). México D.F.: IPGH.

3. Renan, E. (1987) ¿Qué es una nación? / Cartas a Strauss. Madrid: Alianza.

\section{Revista}

1. Revista de Historia, No. 20 y 21, Primero y Segundo Semestre 2006, Managua: IHNCA-UCA.

\section{Artículos electrónicos}

1. Acuña Ortega, V. H. La formación del Estado en Nicaragua y Costa Rica en perspectiva comparada: siglos XIX-XX. 21. En https://www.american.edu/ clals/upload/264n-del-Estado-enNicaragua-y-Costa-Rica-en-perspectivacomparada.pdf (Fecha de consulta: 2 de febrero de 2014).

2. Ayerdis García, M. "La fiesta nacional dariana de 1941 o la canonización de la cultura oficial". En: Revista Istmo http:/ / istmo.denison.edu/n10/articulos / fiesta.html s.p. (Fecha de consulta: 15 de febrero de 2014).

3. Fernández Ampié, G. Variaciones de la idea de nación y patria en los textos escolares de Historia de Nicaragua. 18711930: El arduo camino en la construcción del sentimiento de nacionalidad nicaragüense. Diálogos. Número Especial 2008: 1035. En http:/ / escuelahistoria.fcs. ucr.ac.cr/contenidos/articulos/2008/ especial2008/articulos/04-Cultural/46. pdf (Fecha de consulta: 1 de marzo de 2014). 